\section{IMPACTO Y MANEJO}

Impacto en Cuba: Invade claros abiertos de forma natural o antrópica en todos los ecosistemas y desplaza a las especies nativas. Los bosques de pinos son los más afectados, donde llega literalmente a cubrir el sotobosque excluyendo a todas las demás especies herbáceas.

Sugerencias para el manejo: Aunque no existen experiencias de manejo, la sombra intensa pudiera ser una alternativa para su control, dado que raramente aparece en ecosistemas cerrados, como los bosques pluviales. De igual forma, pudieran ser efectivos la chapea y el arranque de los múltiples estolones que crecen paralelos al suelo y pueden dar origen a nuevas plantas, combinados con la siembra de plantas nativas de rápido crecimiento.

Usos: Las hojas cortadas se emplean como complemento verde en arreglos florales y en decoraciones. Se le reconoce valor ornamental y se le atribuyen propiedades místicas empleándosele en los rituales de limpieza y purificación de la santería, el espiritismo o como decoración en las iglesias cristianas, así como en las celebraciones religiosas sincréticas conocidas como "altares". Además se ha utilizado para curar heridas en la Polinesia Francesa y contra las diarreas en Fiji.
Serie Plantas invasoras

Esta serie se creó para facilitar la identificación y gestión de las especies invasoras más agresivas en Cuba o de marcado interés en algunas áreas protegidas.

\section{Volúmenes de la Serie}

Volumen 1: Introductorio

Volumen 2: Ética en el tratamiento a las especies exóticas

Volumen 3: Dichrostachys cinerea

Volumen 4: Syzygium jambos

Volumen 5: Acacia farnesiana

Volumen 6: Leucaena leucocephala

Volumen 7: Casuarina equisetifolia

Volumen 8: Melaleuca quinquenervia

Volumen 9: Eichhornia crassipes

Volumen 10: Mimosa pigra

Volumen 11: Albizia procera

Volumen 12: Bothriochloa pertusa

Volumen 13: Spathodea campanulate

Volumen 14: Inga punctata

Volumen 15: Myriophyllum pinnatum

Volumen 16: Nephrolepis hirsutula

Volumen 17: Tithonia diversifolia

Volumen 18: Macrothelypteris torresiana

Volumen 19: Schinus terebinthifolius

Volumen 20: Egeria densa

Volumen 21: Hydrilla verticillata

Volumen 22: Pistia stratiotes

Volumen 23: Bromelia pinguin

Volumen 24: Sida ulmifolia

Volumen 25: Heteropogon contortus

Edición: Ramona Oviedo, Iralys Ventosa, Lisbet González-Oliva y Ledis Regalado

Diseño: Josmaily Lóriga

\section{Nephrolepis hirsutula}

Fotografías: Ariel Rodríguez

Ilustraciones: Gustavo Pineda

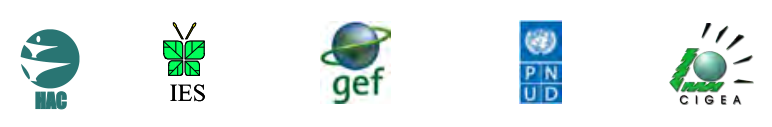

Ante observaciones en nuevas localidades o eventos relevantes para su manejo, comuníquese con los autores

Editado en La Habana, julio de 2011

Serie de folletos informativos sobre

\title{
Plantas invasoras
}

Vol. 16: Nephrolepis hirsutula

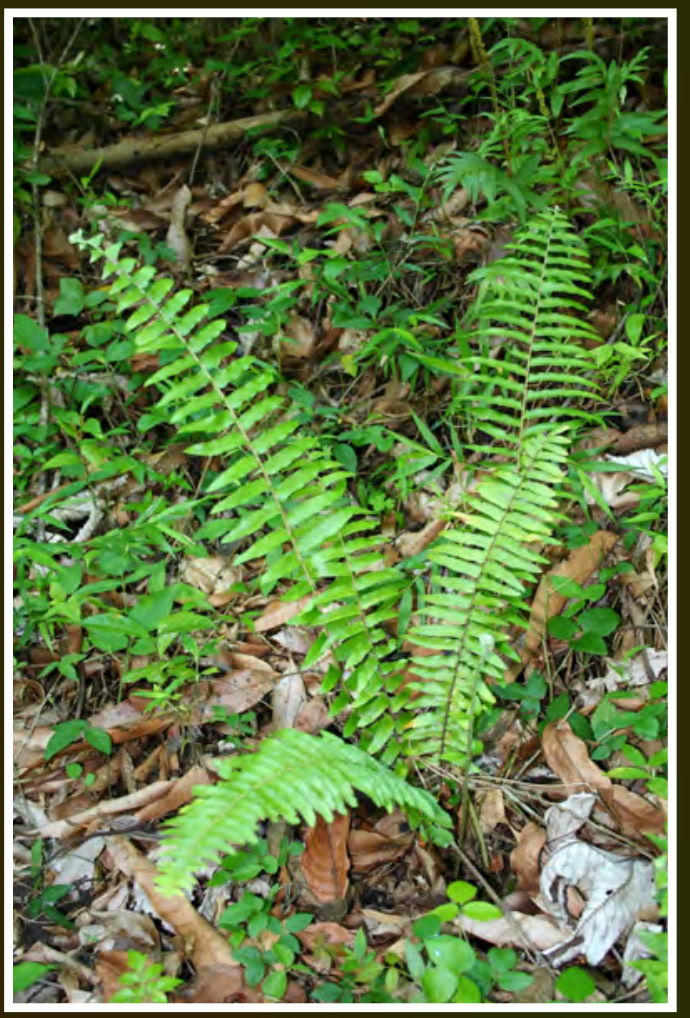

Manuel G. Caluff ${ }^{1}$ y Ledis Regalado 'Jardín de los Helechos de Santiago de Cuba, Centro Oriental de Ecosistemas y Biodiversidad (BIOECO, CITMA), ${ }^{2}$ Instituto de Ecología y Sistemática (AMA, CITMA) E-mails: manolito@bioeco.ciges.inf.cu y ledisregalado@ecologia.cu 


\section{INFORMACIÓN BÁSICA}

Familia: Lomariopsidaceae

Nombre científico

Nephrolepis hirsutula (G. Forst.) C. Presl

Sinónimos más importantes:

Nephrolepis multiflora (Roxb.) F. M. Jarrett ex C. V. Morton Davallia multiflora Roxb.

Nombres comunes: Helecho (en toda Cuba), penquita (Sierra Maestra), puntero (Nipe-Sagua-Baracoa).

Descripción botánica: Hierba perenne (que vive más de dos años), mayormente terrestre, que puede crecer sobre las piedras o sobre otras plantas. Tallo erecto que emite estolones rígidos y ramificados. Las escamas del ápice del tallo, las hojas jóvenes y los pecíolos son bicoloras, pardo-rojizas a negras con un margen blanquecino, fimbriado, 2-3 mm de largo. Hojas erectas, con la lámina una vez pinnada, de hasta $1 \mathrm{~m}$ de largo y 7-20 cm de ancho, con pinnas lineares de márgenes crenados (formando conchas) $\circ$ aserrados. Soros (agrupaciones de esporangios) cerca del margen (submarginales). Indusio (capa epidérmica que recubre y protege al soro) en forma de riñón u orbicular. A diferencia de ésta, especies nativas como Nephrolepis exaltata (L.) Schott presenta escamas amarillentas a pardo claras y Nephrolepis biserrata (Sw.) Schott tiene las escamas pardo claras, los márgenes de sus pinnas ondulados y sus soros situados cerca de la costa (vena media de la pinna).

Fenología: Produce esporas durante todo el año.

Dispersión: Por esporas diseminadas por el viento. También puede propagarse mediante estolones producidos a partir del tallo que originan nuevas plantas en sus extremos.

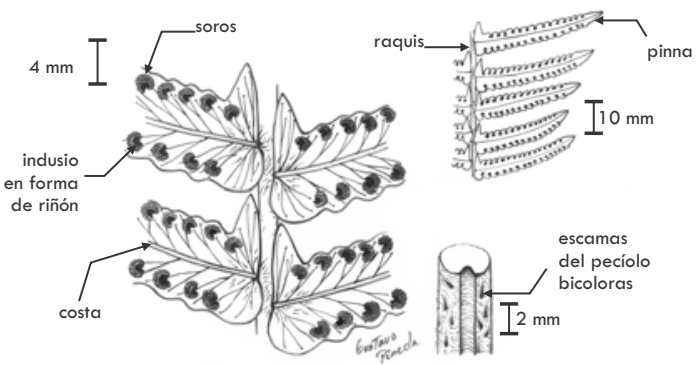

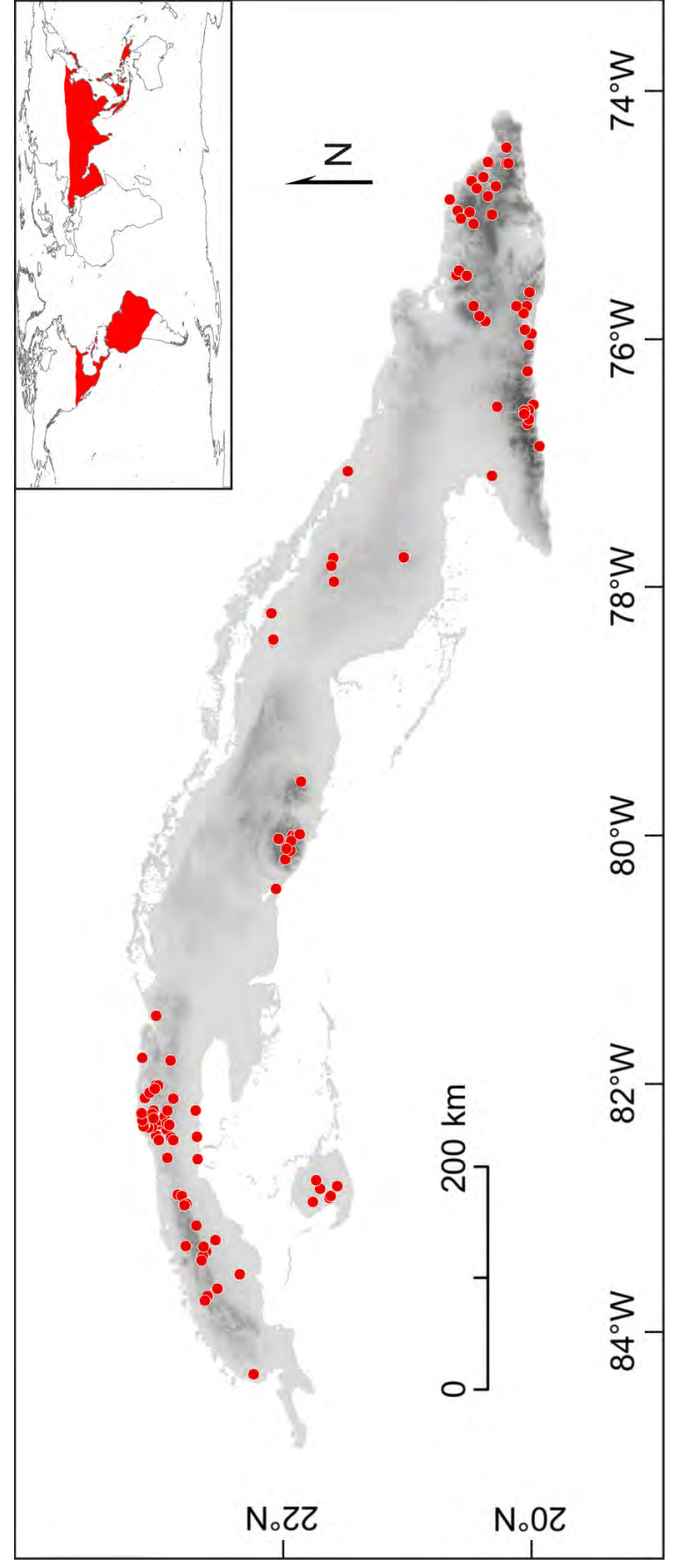

\section{DISTRIBUCION}

Distribución mundial: Nativa de Asia tropical oriental. Fue introducida en La Florida, Estados Unidos como ornamental y ya en 1935 se encontraba naturalizada en la zona de los Everglades. Su distribución actual abarca no sólo Asia tropical y subtropical, sino también las islas del Pacífico y América, donde se ha registrado en Estados Unidos, México, Guatemala, Belice, Honduras, Salvador, Nicaragua, Costa Rica, Panamá, Bahamas, Antillas Mayores y Menores, Colombia, Venezuela, Trinidad, Guyana, Ecuador, Perú, Brasil y Bolivia.

Distribución en Cuba: Sus esporas llegaron por sí mismas probablemente de plantas cultivadas en La Florida. Se registró por primera vez en Cuba en 1944, en la Sierra de Nipe, Holguín. Posteriormente fue recolectada en Punta Gorda, Moa en 1947, en el Cerro de Cananova en 1948, en la Sierra Maestra en 1959, en Cuba central en 1967, en Pinar del Río en 1968 y en la Isla de la Juventud en 1974. Actualmente se encuentra extendida en toda Cuba.

Ecosistemas que invade en Cuba: Esta especie vive desde el nivel del mar hasta los $1900 \mathrm{~m}$ de altitud y en casi todos los ecosistemas. Adopta todos los modos de vida y crece en todo tipo de suelos, aunque prefiere los ácidos de montaña, especialmente los de pinares.

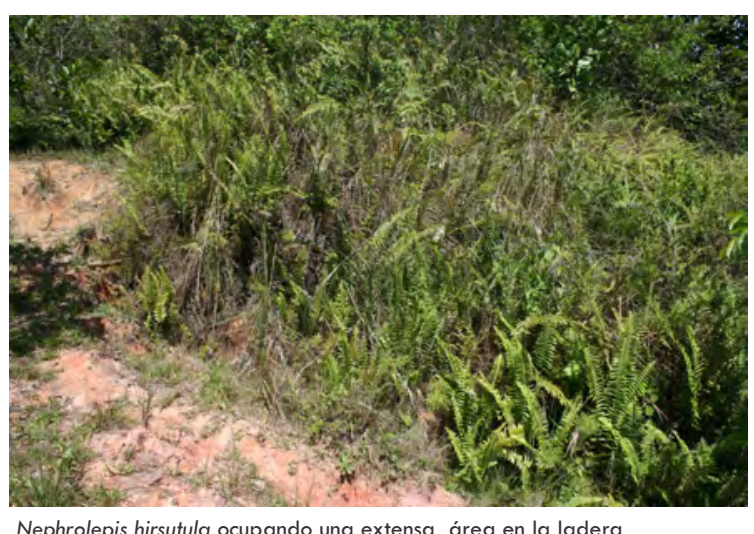

